\title{
Incorporating "Whatsapp" Into a University Vocabulary Development
}

\author{
Fatimatul A'izah ${ }^{1}$
}

${ }^{1}$ Universitas Negeri Bengkulu, Bengkulu, Indonesia meitadzkiyah@yahoo.com

\begin{abstract}
Vocabulary is the most important level of language knowledge for learners to acquire. Knowledge which enables them to participate in listening and speaking activities merit the highest priority for interpersonal contexts. Education system has developed rapidly, technology has attacked our life, everyone has smart phone which is featured by WhatsApp, Facebook, Twitter, Instagram, Telegram, etc. One application which is much interesting for the learners is WhatsApp application. Thus application has been familiar for young generation. It's easier for learners to gain a success in vocabulary input. In this paper, the writer will discuss about vocabulary learning, designing input activities, Activities for teaching vocabulary, and also WhatsApp for vocabulary input; how to incorporating this application to build vocabulary knowledge.
\end{abstract}

Keywords: WhatsApp, Vocabulary learning

\section{INTRODUCTION}

Vocabulary is crucial to English language teaching, because without sufficient vocabulary learners cannot be incorporated into all four language skill. It is the reason why students should construct their vocabulary knowledge in order to enable them in such speaking, writing, listening and reading activity. Having adequate vocabulary will help the L2 learners to communicate actively, or to produce many texts in target language, also to comprehend the listening or reading text.

L2 learners acquire vocabulary knowledge indirectly, by listening others speaker or reading to texts in target language, and then by using words to communicate with others. As novices begin to read and write, they acquire more words through understanding what they are reading or listening and then incorporate those words into their speaking and writing.

\footnotetext{
Vocabulary Learning

Learning other language seems to learn the whole language elements, all vocabularies which exists in that language. This is because (Nation, 2001:12) all words as being of equal value to the learner. While, in lists of frequency words shows that it is not so, and that some words are much more usefull than others. Recent studies by Zechmeister, Chroinis, Cull, D'Anna and Healy (1995) suggest that educated native speaker of English know around 20.000 word families. Not all of those words must be considered as the essential word to be taught in especially EFL context. The consideration of sellecting words can be based on the type of the vocabulary. According to Nation (2001) that four kinds of vocabulary in the text: high frequency words, academic words, technical and low frequency words.
}

1. High Frequency Words is words that are much more frequent and useful in a very wide range of language uses than others. The classic list of high-frequency words is Michael West's (1953) A General Service List of English Words which contains around 2000 word families. These high-frequency words merit a great attention in language teaching.

2. Academic Words is words that are taught for academic purpose. Typically these words coverage $9 \%$ of the running words within academic text. The academic word list (coxhead, 1998) contains 570 headword.

3. Technical word (Nation, 2001) contains some words that are related to the topic and subject area of the text. These words are common in one topic but not so common elsewhere.

4. Low frequency words are words that is not included in high-frequency word, academic word and have no relation to any topic else.

According to Nation and Wang (1999), as long as there is a quite amount of input, there will be much opportunities to strengthen and establish appropriate vocabulary. When learner of L2 receive input vocabulary, so the control of vocabulary is used and new vocabulary gets plenty of repitition. So, why we need an input activity is to control learner's vocabulary. Learners can promote themselves of a quite amount of input, such in interactions participating and author Web pages. When learners participate in an interaction, they will probably receive new vocabulary by other participants. While in Author Web Pages, Carol A. Chapelle (2003) states that unknown people may find web page which is posted and if when they are interested, they can join in a discussion perhaps to benefit from the input without being pressed to produce any language. People who are learning to read and write 
and those who are reading to learn will be helped from a sound instructional vocabulary program (Gibbons, 2009).

L2 Learners with small vocabularies, by which vocabulary is developed through immersion in language activities, knowledge of vocabulary is acquired inciden $\neg$ tally. Words are also learned through direct instruction, where students learn words through a structured approach (Gibbons, 2009). Thus, classroom activity should be designed to support learner's vocabulary learn $\rightarrow$ ing through a combination of approaches to teaching, direct instruction, and incidental word learning. Michael Graves (2006) in Gibbons's book named Tornadoes!, offers a framework for successful vocabulary pro $\neg$ grams that supports effective teaching and students' development of word knowledge. To develop robust vocabularies, an instructional program needs to provide a variety of language practices. By providing varied activities to interact with target vocabulary means enriching learners vocabulary knowledge. According to Nation (2003), Vocabulary input can be succeed in such listening or reading activity. Vocabulary learning is greatly helped when listening if teacher directly defines unfamiliar word (Elley, 1989) and note them on the board. While noting the unfamiliar words, teacher can give a stimulus to the learners by giving order or questions related to what is listened. When input become the source of output, such as listening to a text and answering related question, the relationship between input and output will have big result in vocabulary learning. If the question that follow the listening task accelerate the target vocabulary or to use the target vocabulary that exists in it, or entail to adapt it or expand its applications, so, it will enrich and strengthen the memory of vocabulary. For example a text about "the impact of global warming". The text states Global warming has brought a great impact to the world. One of the most impacts we can feel is uncertain climate change. Many people in this world complain about the temperature of the air in our beloved earth is getting hotter. Nowadays, The level of air pollution in Indonesia, especially in big cities like Jakarta has almost reached the limit of danger. And do you know ladies and gentlement, vehicle fumes created by all society arethe biggest contributions for this case. The question after the text is "how can we solve the problem of global warming? Notice how this question (1) requires the use of target vocabulary, Global Warming, (2) require the learner to expand the meaning of the word, (3) requires to use the word in another context. Therefore, such question can give contribution to the learning of vocabulary and affect on learners' vocabulary knowledge. Such question can also be used in reading activity to give input on vocabulary learning.

A reading comparible of teacher defining words while learners listen is use of a glossary while reading (Nation, 2003). The use of glossary does not always help learner to comprehend the text, but it contributes and affect positively on vocabulary learning. The place of glossary influences its value in reading text. When a reading text glosses at bottom or the end of the text, it will disturb the reading process. So, the best place for glossary is at side of the text. Long (in Watanabe, 1997) offers that looking at such glossary gets considerable attention to a word. The learner sees the word in the text, look at the glossary and thus sees the word for twice, and then looks back at the text that attending to the word for the third time.

\section{METHOD}

Scavenger Hunt (Pages, 2000) suggested there are kind of activities to deal with the goals of vocabulary instruction such as by giving L2 learners a catalog of necessary vocabulary for them. Then, the learners are classified into small groups. After grouping the learners, it's chance to up grade the novelty of vocabularies, expanding the use of new vocabularies into variety of sentences. The next is illustrating the vocabulary words by each groups. Giving score point as appreciation, planning the way how to collect the descriptions of each groups words, assessing how their efforts have been progressing, creating words posters, and the last is playing games related to the vocabularies.

Vocabulary Self-Collection Strategy (Haggard, 1982), proposes some activities to build learners' vocabulary knowledge. The first is asking learners to identify two words that are correlated to specific topics which is discussed, writing down their words on the board, learners are ordered to introduce the words, and reducing the list of vocabulary by eliminating words which are familiar for many learners. The final list becomes the main focus of vocabulary activities for the next few days.

The other activity to teach vocabulary is Word Map (Margosein, 1982. example from Holder, 1997). We can use the word map technique to help learners develop a broad concept of definition. It concentrates on three questions, "What is it?", "What is it like?," and "What are some examples?" (Margosein, 1982) to build up learners awareness about the information "definition" and how that information is organized. The purpose of the Word Mapping strategy is to promote the learners' deeper understanding of words through describing varying relationships between and among words. The steps in doing Word mapping are:

1. Select words for vocabulary instruction as a key to understand the text.

2. Project a blank word map with only one key word on the screen.

3. Think how to explore word relationships and the meaning of the key word or related words.

4. Expand the meaning of the word by examples.

5. Find the definition of the word in a glossary or dictionary.

6. Illustrate its meaning by drawing a picture of the word.

7. The word maps will be used during and after reading to add information about the key words.

Students share their maps with others. Students use the information on their word maps to develop and expand the class map, write new information on the group 
map and are encouraged to revise their own word maps to incorporate these new ideas.

For example, followed picture is proposed by Holder (1997)

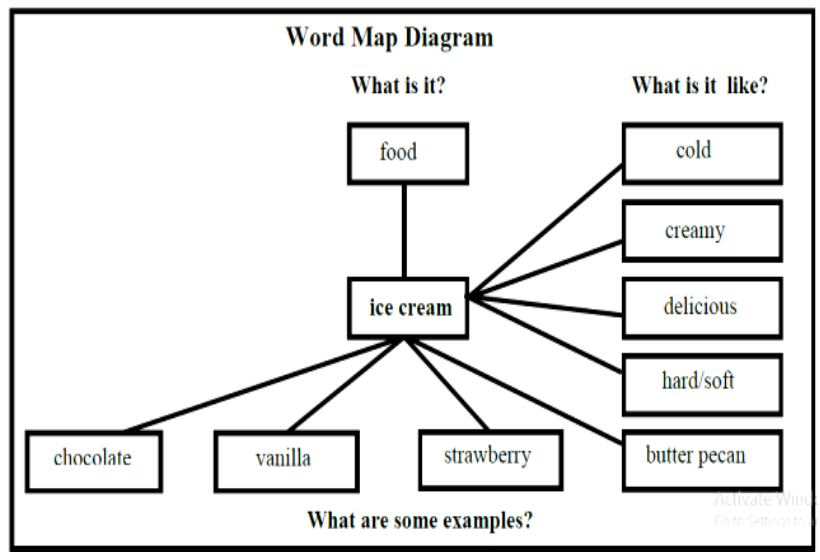

Figure 1. Word map diagram

\section{RESULTS AND DISCUSSION "WhatsApp" APPLICATION TO TALK}

WhatsApp is a fast, simple and reliable way to talk to anyone in the world. More than 1 billion people in over 180 countries use WhatsApp to stay in touch with friends and family. WhatsApp is accessible and reliable, because it's not only free but also available on multiple mobile devices and in low connectivity areas. It's a simple and secure way to share a favorite moments, send important information or catch up with a friend. There are many features in WhatsApp that can help learners to communicate and transfer knowledge via this application. WhatsApp uses phone's Internet connection to send messages. On other side, WhatsApp also can phone and call via video. With voice calls, learners can talk to their friends and family for free, even if they're in another country. And with free video calls, learners can have faceto-face conversations for when voice or text just isn't enough.

Maria (2016) in her study: Use of Whatsapp to Enhance Reading and Writing Skills at Undergraduate College Level, showed that using WhatsApp can be motivation for the learners to improve their writing skills, and learners respond better when technology, especially the internet, is involved in their language learning. The internet which is available on the mobile phones of almost all the students is a highly motivating tool for L2 learning. According to Ghada Awada (2016), the use of WhatsApp mediation was more effective than the regular instruction in improving the critique writing proficiency of the participants. That's why WhatsApp becomes very recomended for facilitating language learning.

The advantages of online communication comparing to face-to-face interaction as follows:(a) the exchanges were viewed as real, not pedagogical; (b) learners developed free and spontaneous, (c) learners expressed deep satisfaction for giving contribution in the target language; and (d) learners benefited substantially from the increased opportunity to practice target language. Through chatting, learners of a language can communicate inexpensively and quickly with other learners or speakers of the target language all over the world.

\section{“WhatsApp" FOR LANGUAGE EXCHANGES \\ Umberto Ansaldo heads the School of Literature,} Arts and Media at the University of Sydney, has been studying and teaching linguistics and languages, Professor Ansaldo says learning has never been as accessible as it is now, especially in language learning. Nowdays, the interaction among people around the world has been supported by many media such as Facebook, Instagram, Tweeter, Skype, Line and WhatsApp. Thare is no space that can block the interaction in all over the world.

By using WhatsApp, language learning institutions can utilize it to develop their learning style or strategy to be more active and progressive. WhatsApp has many features which helps learners to experience language exchange more effectively and spontaneously. The other hand, language institution need to deliberate criteria or factors which can affect on the process of language exchange. The basic criteria for exchange partner is that each partner wishes to learn partner's language. Ideally, not only a native speaker, but a language learner who's proficient can be just as useful to be the partner. However, there are a few other key points to look for, too:

1. Try to find someone who speaks the native language or about as well as participants speak theirs. Such an Indonesian who want to learn English, has to find an American who wish to learn Indonisian Language, or people who are able to communicate in English and willing to learn Indonesian Language.

2. It helps if someone has something in common with the choosen person. The main purpose of the exchange is to improve the language ability, but language exchanges are more successful and more fun when each participant enjoy speaking with each other. Awkward conversations don't make for great learning. Sharing an interest in sports, music or movies has been a solid starting point also.

3. Find out the prospective partner's motivations for improving. If there's a clear objective, the exchange is more likely to last for a decent amount of time. For instance, if someone is looking to learn Spanish for when he/she travels to South America next year and he/she meets a Spanish speaker preparing for a year of study in the USA, they can help each other prepare for those goals.

Once the L2 learners know the kind of partner being looked for, they can start making those connections. The key is using sites that have a page dedicated to language learners searching for WhatsApp exchanges. The website Language Exchange is the perfect example.

\section{INCOPORATING "WhatsApp" INTO A UNIVERSITY VOCABULARY DEVELOPMENT}

A key feature of an organized language exchange is a time limit for each language, e.g. 10 minutes in English, then 10 minutes in German. This may not be so 
formal on WhatsApp, but it's still a good idea for learners to set expectations from the start. The learners don't want to feel short-changed because they are only speaking one language. That isn't much of an exchange! Similarly, make sure learners as "WhatsApp" user give each other an idea of the availability language and how often the message delivered. This is also an incentive to maintain the exchange regularly. Finally, it's good to agree that between participants will correct each other's mistakes. This is helpful and will keep either from taking it individually. The learners supposed to obtain much input in their vocabulary knowledge. In order to be much effective for this goal, the steps need to be planned sistematiccally and structurally. The steps of incorporating "WhatsApp" into vocabulary development are as follow:

\section{Starting "WhatsApp"}

As the first step, the learners are required to join or find their partner for language exchange. It can be found in the website such " mylanguageexchange.com " or joining "Meetup" group. The teacher has to ensure that every learner has an intended partner. It means that the learners find someone who has English as their native language or someone who are almost comunicate like native, and also enthusiasm to learn Indonesian language. Speaking one-on-one to a human being, who speaks the language natively, is infinitely more effective than learning from automated apps, books, or crowded classrooms.

2. Developing Vocabulary knowledge

In this step, the learners start to communicate to their partner. Sometime the teacher order some topic to be discussed with their partner e.g. culture, education, life style. Then, the learners are required to make handout of their activity on WhatsApp and report their progress, make sure that every learners has their own vocabulary list, a list of new vocabulary they learn from their partner.

3. Joining the group chat

After several meeting, when the learners done the task progressively, the teacher facilitates the learners for having an English group chat which consist of participants with different native language and willing to learn English language. Every member of group can open a conversation about where you are and what you're doing. The great thing about WhatsApp is that someone can instantly connect with people in different countries. Share a video of a typical cultural experience from their own country and encourage others to do the same. This is a perfect opportunity to get into vocabulary that might not otherwise known by the learners.

4. Assessing The Vocabulary Development

The teacher can assess learners' vocabulary progress by looking at their vocabulary list. If the vocabulary in the list is increaseing continously, so the learners develop their vocabulary knowledge. The second way to assess learners' progress is from their report in a handout they make about their activity. Teacher can also analyze the learners' vocabulary development trough activity in English group chat. When teacher involved and participate actively to give stimulus or initiate to open a conversation within the group, it will directly define the activity of the learner, do they participate actively? In the conversation occurs within the group, the teacher can directly identify the activities within the group. Scoring rubric is needed to have efficient and consistent grading process. So, Spanish Language and Culture 2015 Scoring Guideline will be used for doing assessment consistently.

\section{CONCLUSIONS}

Vocabulary is consideres as the important part in language learning. It is leveled into four types: High frequency word, Academic Words, Technical Word and Low-Frequency Word. Activities in four language skill can built vocabulary input, such as defining difical word in listening activity. L2 learners can be motivated to obtain vocabulary input by utilizing the WhatsApp application. Thare are some criteria which affect the process of language exchange, they are: the right partner, the same interest between each partners, and prospective partner's motivations. While the steps to do language exchange are:

1. Finding the exchange partner via website or Meetup group. The exchange partner means a person with the same goal to learn new language in intersecting.

2. Developing the vocabulary knowledge according to the course outline. When having chatting in WhatsApp, learners are required to make list of dificult words, and reporting their progress by making handout.

3. After some progress in learners vocabulary achievement, learners will join English group chatting which facilitated by the teachers. In the English group chatting, learners are expected to participate actively within the group.

4. Assessing the vocabulary development by using Spanish Language and Culture 2015 Scoring Guideline.

\section{ACKNOWLEDGMENTS}

I am vary grateful to Allah swt. For the guidence and showing me the way in accomplishing this research. I would like to precise my special thanks of gratitude to $\mathrm{Mr}$, Syafnil for the nonstop support of my study and research, for his guidance, and motivation. Thanks to Graduate State University of Padang that organize the Eighth International Conference on Languages and Arts (ICLA-8) for giving me an opoortunity to present my journal in this seminar. Big thanks to a pair angels who always pray, support, and guide me as long as my life.

\section{REFERENCES}

[1] Abraham Gert van der Vyver, B. W., \& Marais, M. A. (2015). Using Social Media as a Managerial Platform for an Educational Development Project: Cofimvaba. International Journal of Information and Education Technology. 5(12), 910-913. https://doi.org/10.7763/IJIET.2015.V5.636 
[2] Chapelle, Carol A. (2003). English Language Learning and Technology. Philadelphia: John Benjamins Publishing Company.

[3] Elley, W.B. (1989). Vocabulary Acquisition from listening to story. Reading Research Quarterly. 24, (2), 174.

[4] Ghada, A. (2016). Effect of WhatsApp on critique writing proficiency and perceptions toward learning. Cogent Education. 1-26.

[5] Gibbons, G. (2009). Tornadoes! New York: Holiday House.

[6] Haggard, M. R. (1982). The vocabulary selfcollection strategy: An active approach to word learning. Journal of Reading. 26, 203-207.

[7] Khalili. A., \& Baradaran, A. (2009). The Impact of Online Chatting on EFL Learners' Oral Fluency.

[8] Margosein, C. M., Pascarella, E. T., \& Pflaum, S. W. (1982). The effects of instruction using semantic mapping on vocabulary and comprehension. Journal of Early Adolescence. 2(2), 185-194.

[9] Maria, J. (2016). Use of Whatsapp to Enhance Reading and Writing Skills at Undergraduate College Level. Language in India. 16(11).

[10] Nation, I.S.P. (2001). Learning Vocabulary in Another Language. Canbridge: Canbridge University Press.

[11]Nation, Paul. (2003). Material for Teaching Vocabulary. Developing Material for Language Teaching (p. 394-405). New York: Continuum.

[12] Pages, J. M. (2000). Strengthen vocabulary through reading and exploring with a vocabulary scavenger hunt. [On-line]. Available: http://www.kidbibs.com/learningtips/lt24.htm.

[13] Warschauer, M. (1997). Computer-Mediated Collaborative Learning: Theory and Practice. https://doi.org/10.1111/j.1540-4781.1997.tb05514.x

[14] Watanabe, Y. (1997). Input, Intake and Retention: Effects on increased processing on Incidental Learning of Foreign Vocabulary. Studies on Second Language Acquisition. 19. 287-307.

[15] https://www.whatsapp.com/about/ 